\title{
The Healthy Weights Initiative: the first I,000 participants
}

\author{
This article was published in the following Dove Press journal: \\ Patient Preference and Adherence \\ 20 February 2017 \\ Number of times this article has been viewed
}

\section{Mark Lemstra ${ }^{1,2}$ \\ Jeff Fox ${ }^{3}$ \\ Randy Klassen ${ }^{4}$ \\ Dean Dodge 5}

'Alliance Health Medical Clinic, Moose Jaw, ${ }^{2}$ Alliance Health Medical Clinic, Regina, ${ }^{3}$ YMCA of Moose Jaw, ${ }^{4}$ YMCA of Regina, ${ }^{5}$ YMCA of Saskatoon, SK, Canada
Correspondence: Mark Lemstra Alliance Health Medical Clinic, B70, 500 First Avenue North West, Moose Jaw, SK, Canada

$\mathrm{Tel}+\mathrm{I} 3062303911$

Fax +l 3066936202

Email marklemstra@shaw.ca
Background: According to Statistics Canada, the number of adults who are overweight or obese rises every year in Canada. As such, it is obvious that various public policies are not working. After extensive community consultation, the Healthy Weights Initiative (HWI) started in Moose Jaw and expanded to Regina, Saskatchewan, Canada.

Objectives: This study aimed to determine adherence, factors affecting adherence and their impact on various health outcomes.

Methods: From January 2014 to March 2015, 229 participants started the comprehensive 6-month HWI program. It was determined that having a "buddy" and signing a social support contract with three additional family members or friends were important to program adherence. As such, both policies went from being recommended to becoming mandatory. From April 2015 to August 2016, 771 additional participants started the program, allowing evaluation of the two new policies. Moreover, HWI participant adherence was compared to that of 100 new YMCA members.

Results: Among the first 229 HWI participants, 79.9\% completed the 6-month program. After the two new policy changes among the 771 participants, $96.1 \%$ completed the HWI program (risk ratio $=1.20 ; 95 \%$ confidence interval $[\mathrm{CI}]$ : 1.01-1.49). In comparison, among the new YMCA regular members without supervision or assistance, $14.0 \%$ were still fully adhering to their fitness program after 6 months ( $R R=6.85$; 95\% CI: 3.88-12.10). After logistic regression, the only variable with an independent effect for not completing the HWI program was not having a spouse/partner supporting the program (odds ratio $=2.31$; 95\% CI: 1.13-3.67). Although weight loss reductions were obtained (mean: $4.3 \mathrm{~kg}$ ), the more significant benefits observed were health outcomes. For example, the prevalence of depressed mood reduced from $44 \%$ to $16.4 \%(P=0.000)$.

Conclusion: With two new policy changes, including a mandatory "buddy" and a signed social support contract, the HWI has become more successful at promoting program adherence. Moreover, numerous positive health outcomes have been obtained during this free, communitybased initiative.

Keywords: community-based, obesity, social support, program adherence

\section{Introduction}

Being overweight or obese is a more complex health outcome than politicians and public policy experts were originally prepared for. A recent report from Statistics Canada found that the number of adult Canadians being overweight or obese increased from 11,476,904 in 2003 to 14,222,521 in 2014. In each and every single year, the number of adults being overweight or obese increased, from a low rate of annual increase of $0.9 \%$ (in 2010-2011) to a high rate of 3.7\% (2012-2013). In 2014, this equates to $54 \%$ of adult Canadians being overweight or obese $(61.8 \%$ of males and 
$46.2 \%$ of females). Even youth are experiencing challenges. From 2003 to 2014, the number of youths aged 12-17 years and who were overweight or obese increased from 454,905 to $467,969 .{ }^{1}$

From August to December 2013, 153 community consultations were held in the City of Moose Jaw, Saskatchewan, Canada. The results of the consultations revealed that a free, comprehensive obesity reduction program should be the main public health priority for the community (in comparison to other public health programs such as smoking prevention and cessation). Letters of support were obtained from every family doctor, cardiologist and internist in the city, as well as the medical health officer for the local health region. Letters of support were also obtained from the Mayor, City Council, the Chief of Police, the Police Association, the federal Member of Parliament, both provincial Members of the Legislative Assembly, the Minister of Health for Canada, the Moose Jaw Chamber of Commerce, numerous businesses, many community groups, the Heart and Stroke Foundation (SK), the Canadian Cancer Society (SK), the Canadian Diabetes Association (SK), the Canadian Mental Health Association (SK) and the Public Health Agency of Canada. The Healthy Weights Initiative (HWI) started in the city of Moose Jaw on January 1, 2014. Following 121 community consultations in the city of Regina from September 2015 to January 2016, the HWI expanded to Regina on February 1, 2016.

The program components of the HWI have been described in detail previously. ${ }^{2}$ After community input and feedback, HWI protocols also followed other evidence-based recommendations. All ten recommendations from the International Obesity Task Force are included in the program. ${ }^{2,3}$ For dietary intervention, the two main components are reducing caloric intake and following the Canada Food Guide. ${ }^{2,4-6}$ For exercise, participants start with 20 minutes of aerobic activity at $50 \%$ maximal oxygen consumption (max $\mathrm{VO}_{2}$ ), progress to 60 minutes and then gradually progress to $80 \%$ max $\mathrm{VO}_{2} \cdot{ }^{2,7-10}$ The final goal is for each participant to complete 60 minutes of aerobic activity, at $80 \% \max \mathrm{VO}_{2}$, 5 days a week. With cognitive behavioral therapy (CBT), the education sessions discuss barriers, challenge automatic thoughts and behaviors and develop a plan for new thoughts and new behaviors..$^{2,411-13}$ Initially, participating with a buddy of the participants' choice was requested but not mandatory. Moreover, the participants were asked to complete a social support contract with three family members or friends to identify barriers to program completion, strategies and then action plans for family members and friends to assist the participant in overcoming barriers.
There are three objectives of the current study: 1) to determine the impact of the policy change, namely, making the inclusion of a buddy and completing the social support contract mandatory, on program adherence of the first 1,000 HWI participants; 2) to determine adherence levels of 1,000 HWI participants relative to that of 100 new YMCA regular members; and 3) to determine the impact of HWI participation on numerous health outcomes.

\section{Methods}

\section{Setting}

The HWI started in the city of Moose Jaw, Saskatchewan, Canada, on January 1, 2014, and expanded to the city of Regina on February 1, 2016. Both programs were conducted at the local YMCA.

\section{Participants}

All participants had to be an adult with obesity (body mass index [BMI] of $\geq 30 \mathrm{~kg} / \mathrm{m}^{2}$ ) and had to be referred by their medical doctor to help ensure that their physician would provide social support. There were no other inclusion or exclusion criteria.

\section{Pre- and post-HWI measures}

The participants' family doctor was asked to determine the former's blood pressure, blood glucose and blood cholesterol levels. Each participant also completed a standardized fitness test based on guidelines from the Canadian Society for Exercise Physiology, including the Canadian Aerobic Fitness Test (CAFT), as well as measurements of weight, waist and hip and body fat percentage..$^{2,14-16}$

Depressed mood was measured with the valid and reliable Beck Depression Inventory-II (BDI-II). 2,17,18 Depressed mood was defined as a score of 11 or higher on the scale. Physical and emotional health and quality of life was measured with the well-known and validated 36-Item Short Form Health Survey (Short Form-36 or SF-36). ${ }^{2,19}$ Questions on selfreported health and self-reported mental health were taken from the Canadian Comprehensive Health Survey (CCHS) administered by Statistics Canada. Health care utilization was self-reported.

\section{Procedures}

The program was free (no direct or indirect cost), comprehensive and evidence based.

During the initial 12 weeks, each participant received five supervised exercise therapy sessions per week in small groups of eight (60 sessions). In addition, each participant 
also received one group dietary education lecture per week (12 sessions) and one group CBT education lecture per week (12 sessions) for a total of 84 sessions during the initial 12 weeks. During the second 12-week program, each participant was asked to exercise four times per week on their own and once per week with the exercise therapist (12 additional supervised sessions, for a total of 96 supervised exercise sessions over 24 weeks). The second 12-week session included maintenance therapy to try to help ensure participants continue.

After an initial evaluation in March 2015, it was determined that having a buddy participate in the program and signing a social support contract were two important factors predicting adherence. ${ }^{2}$ For example, those not having a family member or friend sign the social support contract were almost three times less likely to complete the program (risk ratio $[R R]=2.90,95 \%$ confidence interval [CI]:1.01-8.34). ${ }^{2}$ Social support is also recommended by the Canadian Society for Exercise Physiology to promote adherence. ${ }^{14}$ Thus, in April 2015, having a buddy and signing the social support contract became mandatory (previously, they were requested but not mandatory).

\section{Ethics}

All participants provided written informed consent for the clinical program and evaluation. The Behavioral Ethics Board of the University of Saskatchewan determined that the study was exempt from ethical review, including the publication of deidentified data (BEH-15-28).

\section{Analysis}

SPSS 22 was used to compare mean scores for before and after program completion with paired-sample $t$-tests. After initial cross-tabulations, binary logistic regression was used to determine the independent association between the outcome variable of not completing the program and the potential explanatory variables. The unadjusted effect of each covariate was determined and then entered one step at a time based on changes in the $-2 \log$ likelihood and the Wald tests. The final results are presented as adjusted odds ratios (ORs) with $95 \% \mathrm{CIs}^{20}$

\section{Results}

Demographic results of the sample are presented in Table 1. The sample of participants differed significantly from the community by gender. Among the first 1,000 HWI participants, $24 \%$ were male and $76 \%$ were female. According to Statistics Canada, in 2011, 48\% of Moose Jaw residents over the age of 15 years were male and $52 \%$ were female. The
Table I Demographics of the first I,000 HWI participants

\begin{tabular}{ll}
\hline Demographics & $\%$ \\
\hline Gender & \\
Male & 24.0 \\
Female & 76.0 \\
Age, years & \\
$65+$ & 3.0 \\
$55-64$ & 22.7 \\
$45-54$ & 25.0 \\
$35-44$ & 26.5 \\
$26-34$ & 17.2 \\
I8-25 & 5.6 \\
Mean age, years & 44.7 \\
Marital status & \\
Married/common law & 73.5 \\
Single & 26.5 \\
Employment & \\
Not employed & 17.6 \\
Nonprofessional & 52.9 \\
Professional & 19.4 \\
Education level & \\
$<$ High school & 6.6 \\
High school & 34.3 \\
College/technical/trades & 42.4 \\
University & 16.4 \\
Medical comorbidities & \\
None & 29.8 \\
I & 33.9 \\
2 & 17.3 \\
\hline Abrevition HWl, & 18.8 \\
\hline
\end{tabular}

Abbreviation: $\mathrm{HWl}$, Healthy Weights Initiative.

other differences were difficult to compare. For example, among the HWI sample, $73.5 \%$ were married or common law, with $26.5 \%$ being single, separated, divorced or widowed. Among Moose Jaw residents over the age of 15 years, 57\% are married, while $43 \%$ are single, separated, divorced or widowed. However, this comparison is not ideal because Statistics Canada defines adulthood at age 15, while the HWI sample only included adults who were of age $\geq 18$ years. In addition, this updated sample of 1,000 participants is nearly identical to the original sample of 229 participants published previously. ${ }^{2}$ For example, in the original sample of $229,25.9 \%$ of the sample was male. In this updated sample of 1,000 participants, $24.0 \%$ are male (Table 1).

From January 2014 to March 2015, 183/229 (79.9\%) participants completed the 6-month HWI program. After program evaluation, participating with a buddy and completing the social support contract with three family members or friends became mandatory. In response, from April 2015 to August 2016, 741/771 (96.1\%) participants completed the HWI program ( $R R=1.20 ; 95 \% \mathrm{CI}$ : $1.01-1.49)$. During the initial 12-week program, adherence to sessions was monitored electronically (exercise) or by documented attendance 
(dietary and CBT education), with $81.5 \%$ attending all 60 exercise therapy sessions, $87.5 \%$ attending all 12 dietary sessions and $80.9 \%$ attending all 12 CBT sessions.

Among the 100 new YMCA regular members in Moose Jaw, who did not receive any known supervision, health care support or social support, 14 (14\%) members were still adhering five times per week to their exercise program at 6 months. Comparing this with the HWI participants of April 2015-August 2016, this results in a rate ratio difference of 6.88 (95\% CI: 3.88-12.10). While 14\% exercised five times per week at 6 months, $48 \%$ were exercising at least once per week and $38 \%$ were not exercising at all.

A full and detailed description of the pre- and post-HWI health results is presented in Table 2 . Statistically significant

Table 2 Health differences in pre- and post-HWI completion parameters

\begin{tabular}{|c|c|c|c|c|}
\hline Factors & Pre-HWI measure & Post-HWI measure & Difference & Significance \\
\hline \multicolumn{5}{|l|}{ Physiological changes } \\
\hline Weight, kg & $108.2(21.6)$ & $103.9(22.1)$ & -4.3 & 0.000 \\
\hline BMI, $\mathrm{kg} / \mathrm{m}^{2}$ & $38.4(6.9)$ & $36.7(6.6)$ & -1.7 & 0.000 \\
\hline Fat, kg & $47.7(12.4)$ & $39.7(12.9)$ & -8.0 & 0.000 \\
\hline Body fat, \% & $48.5(4.1)$ & $44.3(5.1)$ & -4.2 & 0.000 \\
\hline Waist circumference, $\mathrm{cm}$ & II 5.57 (I4.73) & $108.20(13.46)$ & -7.37 & 0.000 \\
\hline Hip circumference, cm & $128.52(16.26)$ & I 22.43 (14.99) & -6.09 & 0.000 \\
\hline Systolic BP, mmHg & I29.4 (I4.6) & $126.0(10.0)$ & -3.4 & 0.000 \\
\hline Diastolic BP, mmHg & $82.6(11.9)$ & $80.4(8.8)$ & -2.2 & 0.000 \\
\hline Blood glucose, $\mathrm{mmoL}$ & $5.7(1.8)$ & $5.6(1.2)$ & -0.1 & 0.081 \\
\hline Blood cholesterol, mmoL & $4.9(1.1)$ & $4.5(1.1)$ & -0.4 & 0.030 \\
\hline CAFT aerobic fitness, score & I20.5 (I I7.I) & $162.0(135.9)$ & +41.5 & 0.000 \\
\hline Length of hard PA/week, minutes & 46.4 & 130.0 & +83.6 & 0.000 \\
\hline Length of moderate PA/week, minutes & 75.4 & 195.5 & $+\mid 20.1$ & 0.000 \\
\hline MSK pain score (average) & $3.6 / 10(0.4)$ & $2.9 / 10(0.5)$ & -0.7 & 0.001 \\
\hline \multicolumn{5}{|l|}{ SF-36 score } \\
\hline Physical functioning & $60.0(21.1)$ & $70.8(22.7)$ & +10.8 & 0.000 \\
\hline Limits - physical & $69.1(31.3)$ & $57.4(29.3)$ & -11.7 & 0.000 \\
\hline Pain & $65.4(20.9)$ & $58.9(20.9)$ & -6.5 & 0.000 \\
\hline General health & $47.8(19.2)$ & $60.2(19.0)$ & +12.4 & 0.000 \\
\hline Vitality & $42.7(16.1)$ & $58.6(16.1)$ & +15.9 & 0.000 \\
\hline Social functioning & $63.0(23.7)$ & $72.2(23.6)$ & +9.2 & 0.000 \\
\hline Limits - emotional & $70.3(31.8)$ & $62.0(28.8)$ & -8.3 & 0.000 \\
\hline Emotional well-being & $58.7(18.2)$ & $67.6(18.4)$ & +8.9 & 0.000 \\
\hline Physical composite score & $43.7(9.2)$ & $48.9(7.7)$ & +5.2 & 0.000 \\
\hline Mental composite score & $46.3(11.4)$ & $51.2(8.2)$ & +4.9 & 0.000 \\
\hline \multicolumn{5}{|l|}{ Depressed mood } \\
\hline BDI-II score & $10.4(7.2)$ & $6.3(6.3)$ & -4.1 & 0.000 \\
\hline Severe/extreme $(3 I+)$ & $1.8 \%$ & $0.3 \%$ & $-1.5 \%$ & \\
\hline Moderate $(2 \mathrm{I}-30)$ & $6.6 \%$ & $4.5 \%$ & $-2.1 \%$ & \\
\hline Borderline (17-20) & $12.9 \%$ & $2.3 \%$ & $-10.6 \%$ & \\
\hline Mild $(1 I-16)$ & $22.7 \%$ & $9.3 \%$ & $-13.4 \%$ & \\
\hline No depressed mood & $56.0 \%$ & $83.6 \%$ & $+27.6 \%$ & \\
\hline Depressed mood (II+) & $44.0 \%$ & $16.4 \%$ & $-27.6 \%$ & 0.000 \\
\hline \multicolumn{5}{|l|}{ Self-reported health } \\
\hline Poor & $16.4 \%$ & $2.3 \%$ & $-14.1 \%$ & 0.000 \\
\hline Fair & $41.9 \%$ & $17.8 \%$ & $-24.1 \%$ & \\
\hline Good & $33.4 \%$ & $50.5 \%$ & $+17.1 \%$ & \\
\hline Very good/excellent & $8.2 \%$ & $28.9 \%$ & $+20.7 \%$ & \\
\hline \multicolumn{5}{|l|}{ Self-reported mental health } \\
\hline Poor & $3.8 \%$ & $0 \%$ & $-3.8 \%$ & 0.000 \\
\hline Fair & $17.1 \%$ & $8.0 \%$ & $-8.9 \%$ & \\
\hline Good & $44.1 \%$ & $45.5 \%$ & $+1.4 \%$ & \\
\hline Very good/excellent & $35.0 \%$ & $46.5 \%$ & $+11.5 \%$ & \\
\hline
\end{tabular}

(Continued) 
Table 2 (Continued)

\begin{tabular}{|c|c|c|c|c|}
\hline Factors & Pre-HWI measure & Post-HWI measure & Difference & Significance \\
\hline \multicolumn{5}{|l|}{ Health care utilization } \\
\hline Doctor visits (mean) ${ }^{\mathrm{a}}$ & I.8 (0.4) & I.3 (0.5) & -0.5 & 0.061 \\
\hline Hospitalizations $^{\mathrm{a}}$ & & & & 0.072 \\
\hline 0 & $74.5 \%$ & $82.7 \%$ & $+8.2 \%$ & \\
\hline 1 & $14.4 \%$ & $12.5 \%$ & $-1.9 \%$ & \\
\hline 2 & $3.3 \%$ & $3.1 \%$ & $-0.2 \%$ & \\
\hline$\geq 3$ & $7.8 \%$ & $1.7 \%$ & $-6.1 \%$ & \\
\hline Medications (mean) & $1.4(0.3)$ & $1.2(0.4)$ & -0.2 & 0.073 \\
\hline Smoking & & & & 0.000 \\
\hline Daily smoker & $16.2 \%$ & $10.6 \%$ & $-5.6 \%$ & \\
\hline \multicolumn{5}{|c|}{ Dietary behaviors (consumption/day) } \\
\hline Meat & I.3 $(0.7)$ & I.4 (0.8) & +0.1 & 0.056 \\
\hline Fruit & $1.3(1.1)$ & $2.1(1.2)$ & +0.8 & 0.000 \\
\hline Vegetables & $1.7(1.1)$ & $2.3(1.2)$ & +0.6 & 0.000 \\
\hline Milk & $0.8(1.0)$ & $0.9(1.0)$ & +0.1 & 0.069 \\
\hline Popular food & $0.7(I . I)$ & $0.3(0.7)$ & -0.4 & 0.001 \\
\hline Fast food & $\mathrm{I} .4(\mathrm{I} . \mathrm{I})$ & $0.9(0.8)$ & -0.5 & 0.000 \\
\hline
\end{tabular}

Notes: The values in the pre-HWI measure and post-HWI measure columns were presented as mean (SD) or \%. ${ }^{\text {aD }}$ octor visits and hospitalizations are measured from 3 months before the program started and 3 months after the program.

Abbreviations: BDI, Beck Depression Inventory; BMI, body mass index; BP, blood pressure; CAFT, Canadian Aerobic Fitness Test; HWI, Healthy Weights Initiative; MSK, musculoskeletal; PA, physical activity; SD, standard deviation; SF-36, 36-Item Short Form Health Survey.

positive changes were obtained for weight loss $(4.3 \mathrm{~kg})$, BMI $\left(1.7 \mathrm{~kg} / \mathrm{m}^{2}\right)$, fat loss $(8.0 \mathrm{~kg})$, body fat percentage $(4.2 \%)$, waist circumference ( 3 in), hip circumference ( 2.4 in), systolic blood pressure $(3.4 \mathrm{mmHg})$, diastolic blood pressure (2.2 $\mathrm{mmHg})$, blood cholesterol $(0.4 \mathrm{mmoL})$, CAFT aerobic fitness score (41.5), duration of hard (83.6 minutes) and moderate (120.1 minutes) physical activity per week and average musculoskeletal pain score ( 0.7 out of total pain score of 10). There was no statistically significant change in the pre- to post-HWI blood cholesterol scores.

The SF-36 health-related quality-of-life survey has eight dimensions and two composite scores. Statistically significant differences were found in all dimensions, including physical functioning, limits to physical functioning, pain, general health, vitality, social functioning, limits to emotional functioning, emotional well being, as well as the physical composite score and the mental composite score (Table 2).

Prior to starting the program, $44 \%$ of participants had depressed mood, while only $16.4 \%$ had depressed mood upon completion of the program (measured by BDI-II, with a cutoff score of 11). In Table 2, the results are presented by severity to clarify that the majority of the reduction of depressed mood occurred in the mild and borderline depressed-mood cases.

Although there were small reductions in health care utilization for physician visits, hospitalizations and medication usage, none of the results were statistically significant (Table 2).
There were statistically significant changes in self-reported health and self-reported mental health. Among dietary behaviors, there were positive changes in self-reported consumption of fruits, vegetables, as well as popular and fast food but no statistically significant changes in meat or milk consumption (Table 2).

\section{Independent risk factors for noncompletion}

Out of the 1,000 initial HWI participants, 76 did not complete the program. Among these, 58 were females and 18 were males. Among females, the primary reason for not completing the program was not having active support from a male spouse or partner (51/58 or $88 \%)$. Among males, not completing the program, the primary reason was having a medical procedure booked (ie, elective knee surgery), with $8 / 18$ (44\%) stating this as the cause of nonadherence.

After logistic regression, the only variable with an independent effect for not completing the program was not having a spouse/partner actively supporting the program $(\mathrm{OR}=2.31$; 95\% CI: 1.13-3.67). Other family members or friends were supporting the program, but not the spouse or partner.

\section{Discussion}

The HWI is a supervised weight loss program. After implementing a mandatory buddy system for social support, along with a mandatory social support contract signed by three family members or friends, program adherence increased 
from $79.9 \%$ to $96.1 \%(\mathrm{RR}=1.20 ; 95 \% \mathrm{CI}: 1.01-1.49)$. This importance of social support is well documented in the literature. ${ }^{21-23}$ It appears that combining clinical supervision with a buddy system and social support is what is required to promote better adherence.

Consistent with this finding, there were also significant differences between 6-month adherence levels between HWI participants and new, regular YMCA members joining the fitness center for the first time, with the latter not having any known supervision, health care assistance or social support ( $\mathrm{RR}=6.88$; 95\% CI: 3.88-12.10).

After logistic regression, the only variable with an independent effect for not completing the HWI program was not having a spouse or partner supporting the program (OR $=2.31$; 95\% CI: 1.13-3.67). Although HWI participants were originally encouraged, and later mandated, to have three family members or friends sign social support contracts, the contract did not specify that it had to include spouses or partners. The impact of spouses or partners was especially important on females who did not complete the program because $88 \%$ of females self-reported that the main reason for not finishing the program was lack of active social support from their male partner. The authors were not able to find any studies that suggest which family members are more important than others for providing social support. In our study, the results suggest that spouses or partners should be included in the social support contract. This component will be included in future HWI programs.

Comparing our results to those of other studies, a recent systematic literature review and meta-analysis reviewed adherence and factors promoting adherence in weight loss programs..$^{24}$ Overall, $60.5 \%$ adhere to weight loss programs (95\% CI: 53.6-67.2). Adherence is obviously lower for realworld observational studies than in randomized clinical trials where participants are often paid to adhere and have one-onone supervision. In the cited meta-analysis, interventions that offered supervision had higher adherence than those that did not ( $\mathrm{RR}=1.65 ; 95 \% \mathrm{CI}: 1.54-1.77)$. In addition, programs that had social support were also more likely to have higher adherence (RR $=1.29$; $95 \%$ CI: $1.24-1.34)$.

\section{Study limitations}

The HWI program is a real-world observational study and not a randomized controlled trial.

\section{Conclusion}

With two new policy changes, including a mandatory "buddy" and a signed social support contract with three family members or friends, the HWI has become more successful at promoting program adherence. In addition, numerous positive health outcomes have been obtained during this free, community-based initiative.

\section{Acknowledgments}

The authors extend special thanks to the YMCA of Moose Jaw and the YMCA of Regina. Partial funding for this study was obtained from the Public Health Agency of Canada (1516-HQ-000036). The views expressed herein do not necessarily represent the views of the Public Health Agency of Canada.

\section{Disclosure}

The authors report no conflicts of interest in this work.

\section{References}

1. Statistics Canada. Health Indicator Profile, Annual Estimates, by Age Group and Sex, Canada, Provinces, Territories, Health Regions and Peer Groups. Statistics Canada; 2016:1-4.

2. Lemstra M, Rogers MR. The importance of community consultation and social support in adhering to an obesity reduction program: results from the Healthy Weights Initiative. Patient Prefer Adherence. 2015;9: $1473-1480$.

3. Kumanyika S, Jeffery RW, Morabia A, Ritenbaug C, Antipatis VJ. Public Health Approaches to the Prevention of Obesity (PAHPO) Working Group of the International Obesity Task Force (IOTF). Int $J$ Obesity. 2002;26:425-436.

4. Laddu D, Dow C, Hingle M, Thomson C, Going S. A review of evidence-based strategies to treat obesity in adults. Nut Clin Pract. 2011; 26(5):512-525.

5. Romaguera D, Norat T, Mouw T, et al. Adherence to the Mediterranean diet is associated with lower abdominal adiposity in European men and women. J Nutr. 2009;139(9):1728-1737.

6. Panagiotakos DB, Chrysohoou C, Pitsavos C, Stefanadis C. Association between the prevalence of obesity and adherence to the Mediterranean diet: the ATTICA study. Nutrition. 2006;22(5):449-456.

7. Howley E, Franks B. Health Fitness Instructor's Handbook. 4th ed. Champaign, IL: Human Kinetics; 2003.

8. Willis LH, Slentz CA, Bateman LA, et al. Effects of aerobic and/or resistance training on body mass and fat mass in overweight or obese adults. J Appl Physiol. 2012;113(12):1831-1837.

9. Garber CE, Blissmer B, Deschenes MR, et al. American College of Sports Medicine position stand. Quantity and quality of exercise for developing and maintaining cardiorespiratory, musculoskeletal, and neuromotor fitness in apparently healthy adults: guidance for prescribing exercise. Med Sci Sports Exerc. 2011;43(7):1334-1359.

10. Willis FB, Smith FM, Willis AP. Frequency of exercise for body fat loss: a controlled, cohort study. J Strength Cond Res. 2009;23(8): 2377-2380.

11. Christakis NA, Fowler JH. The collective dynamics of smoking in large social network. N Eng J Med. 2008;358(21):2249-2258.

12. Wing RR, Jeffery RW. Benefits of recruiting participants with friends and increasing social support for weight loss and maintenance. J Consult Clin Psychol. 1999;67(1):132-138.

13. Murphy JK, Willimson DA, Buzton AE, Moody SC, Absher N, Warner M. The long-term effects of spouse involvement upon weight loss and maintenance. Behav Ther. 1982;13(5):681-693.

14. Canadian Society for Exercise Physiology. Physical Activity Training for Health - Resource Manual. Ottawa, ON: Canadian Society for Exercise Physiology; 2013. 
15. Canadian Fitness and Lifestyle Research Institute. Physical Activity Monitor. Ottawa, ON: Canadian Fitness and Lifestyle Research Institute; 1995.

16. Canadian Society for Exercise Physiology. The Canadian Physical Activity, Fitness, and Lifestyle Approach (CMAFLA). 3rd ed. Ottawa, ON: Canadian Society for Exercise Physiology; 2003.

17. Beck AT, Steer RA, Brown GK. Manual for the Beck Depression Inventory-II. San Antonio, TX: Psychological Corporation; 1996.

18. Segal DL, Coolidge FL, Cahill BS, O'Riley AA. Psychometric properties of the Beck Depression Inventory-II (BDI-II) among communitydwelling older adults. Behav Modif. 2008;32(1):3-20.

19. Ware JE, Kosinski M, Keller SD. SF-36 Physical and Mental Health Summary Scales: A Users' Manual. Boston, MA: The Health Institute; 1994.

20. Rothman KJ, Greenland S. Modern Epidemiology. 2nd ed. Philadelphia, PA: Lippincott Williams \& Wilkins; 1998.
21. Abildso CG, Zizzi S, Fitzpatrick SJ. Predictors of clinically significant weight loss and participant retention in an insurance-sponsored, community-based weight management program. Health Promot Pract. 2013;14(4):580-588.

22. Wing RR, Jeffery RW. Benefits of recruiting participants with friends and increasing social support for weight loss and maintenance. J Consult Clin Psychol. 1999;67(1):132-138.

23. Murphy JK, Williamson DA, Buxton AE, Moody SC, Absher N, Warner M. The long-term effects of spouse involvement upon weight loss and maintenance. Behav Ther. 1982;13(5):681-693.

24. Lemstra M, Bird Y, Nwankwo C, Rogers M, Moraros J. Weight loss intervention adherence and factors promoting adherence: a meta analysis. Patient Prefer Adherence. 2016;10:1547-1559.

Patient Preference and Adherence

\section{Publish your work in this journal}

Patient Preference and Adherence is an international, peer-reviewed, open access journal that focuses on the growing importance of patient preference and adherence throughout the therapeutic continuum. Patient satisfaction, acceptability, quality of life, compliance, persistence and their role in developing new therapeutic modalities and compounds to optimize clinical outcomes for existing disease states are major areas of interest for the journal. This journal has been accepted for indexing on PubMed Central. The manuscript management system is completely online and includes a very quick and fair peer-review system, which is all easy to use. Visit http://www. dovepress.com/testimonials.php to read real quotes from published authors.

Submit your manuscript here: http://www.dovepress.com/patient-preference-and-adherence-journal 